\title{
BUKAN JALAN BUNTU, MELAINKAN SETAPAK TERJAL \\ Sebuah Apresiasi Kritis terhadap Sumbangsih Teori Kultural-Linguistik \\ Lindbeck bagi Penumbuhkembangan Dialog \\ Antaragama yang Autentik
}

\section{Risang Anggoro Elliarso*}

"When love beckons to you follow him, though his ways are hard and steep."

Jibrān Khalīl Jibrān

\begin{abstract}
Advancing from his criticism against two principal theological theories of religion, namely: (1) cognitive-propositional theory and (2) experiential-expressive theory, George A. Lindbeck proposes his cultural-linguistic theory as an alternative theory which is deemed more adequate in comprehending plurality of religions. Regrettably, for some, Lindbeck's theory is considered rather as a closure to any interreligious dialogue, as a consequence of its superfluous emphasis on the incommensurability and untranslability amongst different religions. Therefore, within this modest article, taking into account several insights from postcolonial studies, I try to venture a critical appreciation on how Lindbeck's culturallinguistic theory might contribute to the endeavour of fostering constructive, authentic, and profound interreligious dialogue. I attempt to argue that Lindbeck's cultural-linguistic theory, instead of imparting a cul-de-sac to any interreligious dialogue, actually lay bare a path for the dialogue. A path which is, whilst hard and steep, viable.
\end{abstract}

Keywords: George A. Lindbeck, cultural-linguistic theory, interreligious dialogue, postcolonial studies, hybridization, bilingualism, multilingualism, multiple religious belonging.

* Warga jemaat Gereja Kristen Jawa Condongcatur. Email: raelliarso@gmail.com. 


\begin{abstract}
Abstrak
Bertolak dari kritiknya terhadap dua tipe utama teori teologis mengenai agama, yakni: (1) teori kognitif-proposisional dan (2) teori eksperiensial-ekspresif, George A. Lindbeck mengajukan teori kultural-linguistik sebagai sebuah teori alternatif yang lebih memadai dalam rangka mempermaknai pluralitas agama. Sayangnya, bagi sebagian pihak, teori yang diajukan Lindbeck tersebut dipandang justru menutup pintu bagi dialog antaragama, karena terlalu menekankan ketaksepadanan dan ketakterjemahkanan di antara agama yang satu dengan yang lainnya. Oleh sebab itu, dalam artikel sederhana ini, dengan mempertimbangkan beberapa tilikan dari kajian poskolonial, saya berupaya untuk mengapresiasi secara kritis sumbangsih teori kultural-linguistik Lindbeck bagi upaya menumbuhkembangkan dialog antaragama yang konstruktif, autentik, serta mendalam. Saya berupaya untuk menunjukkan bahwa teori kultural-linguistik Lindbeck, alih-alih menghadirkan jalan buntu bagi dialog antaragama, sejatinya justru membuka sebuah setapak yang, meski terjal, bukannya tidak mungkin ditempuh.
\end{abstract}

Kata-kata kunci: George A. Lindbeck, teori kultural-linguistik, dialog antaragama, kajian poskolonial, hibridisasi, bilingualisme, multilingualisme, multiple religious belonging.

\title{
PENGANTAR
}

"Keberatan terbesar kepada pendekatan yang kami adopsi adalah bahwa (pendekatan) itu membuat dialog antaragama menjadi kian sulit," tukas George A. Lindbeck. "Mereka yang memandang bahwa percakapan sebagai kunci pemecahan permasalahan-permasalahan antaragama kemungkinan besar memang akan kecewa," imbuhnya (1997: 427). Dalam hal ini, pendekatan yang Lindbeck maksud adalah pendekatan atau teori kultural-linguistik mengenai agama yang ia usulkan sendiri. Lindbeck rupanya sadar betul bahwa pendekatan atau teori yang ia usulkan tersebut kemudian menuai banyak kritik dan keberatan dari pihak-pihak yang menaruh harapan besar kepada upaya-upaya dialog interreligius sebagai kunci pemecahan permasalahanpermasalahan antaragama, khususnya antagonisme kelompok (group antagonism) di antara pemeluk atau kelompok agama yang berbeda-beda. ${ }^{1}$ 
Bagi mereka yang berkeberatan dengannya, pendekatan kultural-linguistik Lindbeck dipandang terlalu menekankan ketidaksepadanan (incommensurability) dan ketakterjemahkanan (untranslability) di antara agama yang satu dengan yang lainnya. Singkatnya, Lindbeck dipandang terlampau menekankan perbedaan radikal di antara agama-agama yang berbedamasing-masing agama adalah sesuatu-yang-sama-sekali-lain (the wholly other) bagi agamaagama yang lainnya. Dalam hal ini, Marriane Moyaert, misalnya, menyatakan:

Model kultural-linguistik lebih terarah kepada sikap membiarkan yang lain tetap mengada dalam
keberlainannya (otherness) ketimbang kepada upaya memahami yang lain dalam keberlainannya.
Teori agama ini tidak membuka jalan bagi hermeneutik interreligius, melainkan lebih terhubung
dengan semboyan multikulturalistis: Pagar yang baik menciptakan kehidupan bertetangga yang
baik pula. Model kultural-linguistik tidak hanya menggerogoti kemungkinan hermeneutis dari
dialog interreligius; model tersebut juga mengecilkan kepentingan teologis dari dialog-dialog
tersebut (2010: 70).

Senada dengan Moyaert, David R. Brockman pun menandaskan:

... pendekatan kultural-linguistik mematahkan semangat orang-orang Kristen untuk berjumpa dengan umat agama lain (religious other), membuat mereka berpaling ke dalam dan hanya terutama memikirkan apa yang "diketahui" dalam situasi Kristen. Pendekatan kultural-linguistik membuat percakapan interreligius menjadi tampak sulit, bahkan tak mungkin dilakukan... posliberalisme mengubah agama dari sebuah prisma (untuk memandang dunia) menjadi sebuah penjara (2011: 99).

Namun, benarkah pendekatan atau teori kultural-linguistik yang Lindbeck usung memang, meminjam ungkapan Moyaert, menggerogoti kemungkinan dialog interreligius, bahkan meremehkan kepentingan teologisnya? Bukankah Lindbeck sendiri, sebagaimana telah disinggung di atas, sekadar menyatakan bahwa, dalam model kultural-lingusitik, dialog-dialog antaragama "sekadar" menjadi kian sulit?

Tulisan sederhana ini saya tujukan untuk, sedapat mungkin, menjernihkan persoalan tersebut. Dalam tulisan ini, saya akan menelisik dan menimbang model kultural-lingusitik Lindbeck dalam kaitannya dengan upaya menumbuhkembangkan dialog-dialog antaragama. Saya akan mencoba berargumentasi bahwa, di satu sisi, model kultural-linguistik Lindbeck bukannya sama sekali menutup kemungkinan bagi percakapan interreligius yang autentik dan konstruktif. Di sisi lain, saya juga akan, secara serba terbatas, mengajukan beberapa catatan kritis bagi model kultural-linguistik Lindbeck. Namun, sebelum melangkah lebih jauh, pertama-tama, saya akan menghadirkan sebuah sketsa mengenai pendekatan atau teori kultural-linguistik yang diajukan oleh teolog Lutheran asal Amerika yang disebut-sebut sebagai bapa teologi posliberal itu. 


\section{TEORI KULTURAL-LINGUISTIK MENGENAI AGAMA DALAM SELAYANG PANDANG}

Menurut Lindbeck, terdapat dua tipe utama teori teologis mengenai agama, yakni: (1) teori kognitif-proposisional dan (2) teori eksperiensial-ekspresif. Dan, baginya, keduanya sama-sama tidak bisa memberikan tilikan yang memadai mengenai pluralitas agama.

Teori kognitif-proposisional sangat menekankan aspek kognitif dari agama. Doktrindoktrin agama dipandang terutama sebagai proposisi-proposisi informatif atau klaim-klaim kebenaran mengenai realitas yang objektif. Alhasil, dalam teori ini, menurut Lindbeck, agama diperlakukan tak ubahnya sains atau filsafat (1984: 16).

Ditinjau dari titik tilik teori kognitif-proposisional, para pemeluk agama yang berbedabeda tidak mungkin berdialog dan tiba pada suatu kesepakatan atau kesepahaman bersama, karena akan senantiasa ada bukan hanya perbedaan di antara klaim-klaim kebenaran masingmasing agama, melainkan juga pertentangan. Dalam hal ini, Lindbeck menyatakan: "Bagi seorang proposisionalis, jika suatu doktrin adalah benar, maka (doktrin) itu akan selamanya benar, dan jika (doktrin) itu adalah salah, maka (doktrin) itu pun akan selamanya salah. Implikasinya adalah (doktrin-doktrin tersebut)... tidak mungkin diselaraskan. Kesepahaman baru bisa terjadi ketika salah satu atau kedua pihak telah sama sekali meninggalkan posisinya yang semula" (1984: 16).

Dengan kata lain, bagi Lindbeck, ditinjau dari titik tilik teori kognitif-proposisional, kesepahaman dalam sebuah dialog antaragama baru bisa dicapai ketika salah satu atau semua mitra dialog telah meninggalkan ajaran agamanya. Namun, jika hal ini terjadi, per definitionem, dialog tersebut tidak lagi bisa dikatakan sebagai dialog antaragama.

Sementara, dalam teori eksperiensial-ekspresif, agama terutama dipandang sebagai ungkapan dari pengalaman batiniah (inner experience) dalam diri seseorang. Sejalan dengan rumusan itu, doktrin-doktrin agama pun dipandang terutama sebagai upaya-upaya untuk mengungkapkan atau mengutarakan pengalaman batiniah tersebut (Lindbeck, 1984: 16). Secara khusus, Lindbeck menaruh perhatian yang lebih besar kepada teori eksperiensial-ekspresif. Oleh sebab itu, dalam The Nature of Doctrine, Lindbeck pun mengelaborasi lebih lanjut pandangannya mengenai teori tersebut. Dan, baginya, beberapa karakteristik utama teori eksperiensial-ekspresif dapat dijumpai dalam tesis-tesis Bernard Lonergan mengenai agama dalam karya seminal-nya, Method in Theology.

Pertama-tama, Lonergan menyatakan bahwa agama-agama yang berbeda-beda adalah ungkapan-ungkapan atau objektifikasi-objektifikasi dari suatu pengalaman inti (core experience) 
yang sama. Selanjutnya, bagi mendiang filsuf, teolog, sekaligus imam Yesuit asal Kanada tersebut, pengalaman inti tersebut sejatinya dirasakan oleh setiap orang. Pengalaman inti tersebut disadari oleh setiap orang, meski tidak semuanya disadari di aras refleksi yang mawas diri (self-concious reflection). Menurut Lonergan, pengalaman inti inilah yang menjadi sumber sekaligus norma bagi ungkapan-ungkapan atau objektifikasi-objektifikasinya dalam pelbagai agama (Lindbeck, 1984: 31).

Secara spesifik, Lonergan menyatakan pengalaman inti tersebut sebagai “anugerah kasih Allah" (God's gift of love), di mana seseorang merasakan bahwa dirinya berada dalam suatu keadaan dinamis dikasihi secara tanpa batas oleh Allah. Pengalaman akan anugerah kasih Allah inilah yang, menurutnya, dinyatakan oleh Rudolf Otto sebagai mysterium fascinans et tremendum (misteri ketakjuban sekaligus kegentaran), oleh Paul Tilich sebagai keadaan didekap oleh keprihatinan ultim (grasped by ultimate concern), dan oleh Ignatius Loyola sebagai penghiburan nir sebab (consolation that has no cause) (Lindbeck, 1984: 31). ${ }^{2}$

Dengan demikian, ditinjau dari titik tilik teori eksperiensial-ekspresif, dialog antaragama menjadi sangat mungkin dilakukan. Oleh sebab itulah, menurut Lindbeck, teori atau model eksperiensial-ekspresif menjadi sangat menarik bagi mereka yang mengupayakan dialogdialog antaragama. "Model tersebut, “ tukas Lindbeck, "sangat cocok untuk menyediakan suatu rationale bagi dialog dan kerja sama antaragama yang sangat dibutuhkan dalam dunia yang terbelah sekaligus semakin menyusut ini” (1984: 23).

Namun, sayangnya, menurut Lindbeck, dialog-dialog tersebut cenderung menjadi dangkal karena para ekspresionalis-ekspresivis kerap kali melompat terlalu cepat pada kesimpulan bahwa kesepahaman dan kesepakatan antaragama sangat mungkin diwujudkan karena perbedaan di antara agama-agama hanyalah bersifat superfisial. Mereka, misalnya, dengan gegabah menyatakan bahwa semua agama, pada dasarnya, mengajarkan "kasih". Mereka abai belaka bahwa "kasih" dipahami dan dimaknai secara berbeda dalam agama-agama yang berbeda. Dalam hal ini, Lindbeck menandaskan: "Datum bahwa semua agama mengajarkan sesuatu yang bisa disebut sebagai 'kasih' kepada hal yang dianggap paling penting ('Allah') adalah sebuah banalitas.... Yang lebih penting adalah pola-pola khas dari kisah, keyakinan, ritual, serta perilaku yang memberi makna yang tidak hanya spesifik, tetapi juga saling bertentangan, mengenai 'kasih' maupun ‘Allah' (dalam agama-agama yang berbeda)” (1984: 42).

Bertolak dari pandangannya mengenai ketidakmemadaian kedua tipe teori mengenai agama tersebutlah, Lindbeck mengajukan teori kultural-linguistiknya sebagai sebuah alternatif. ${ }^{3}$ Dalam teori kultural-linguistik ini, "agama-agama (dipandang) menyerupai bahasa-bahasa 
beserta bentuk-bentuk kehidupan yang terkait dengannya dan, maka dari itu, juga menyerupai budaya-budaya" (Lindbeck, 1984: 18).

Dalam mengonseptualisasikan agama sebagai fenomena yang menyerupai bahasa (language-like), dengan terbuka, Lindbeck mengakui bahwa ia menimba pengaruh dari pemikiran Ludwig Wittgenstein mengenai bahasa-atau, secara lebih spesifik, "permainan bahasa" (language game). "Pengaruh Wittgenstein... telah menjadi stimulus besar bagi pemikiran saya," tegas Lindbeck (1984: 24). ${ }^{4}$

Dalam pemikiran Wittgenstein, makna dari setiap ungkapan dalam suatu bahasa tidak hanya ditentukan oleh gramatika bahasa tersebut, tetapi juga oleh bentuk-bentuk kehidupan yang berkorelasi dengan bahasa tersebut. Keseluruhan gramatika dan bentuk-bentuk kehidupan itulah yang Wittgenstein nyatakan sebagai permainan bahasa. Tanpa memahami permainan bahasa, menurut Wittgenstein, seseorang tidak akan dapat memahami makna suatu ungkapan bahasa (Hovey, 2002: 138-139).

Bagi Lindbeck, agama adalah serupa dengan apa yang dinyatakan Wittgenstein sebagai permainan bahasa tersebut, di mana doktrin atau ajaran agama berperan seperti halnya gramatika, sementara praktik-praktik religius yang terkait dengan doktrin atau ajaran tersebut adalah seperti halnya bentuk-bentuk kehidupan yang berkorelasi dengan gramatika bahasa:

... seperti halnya bahasa (atau "permainan bahasa" jika kita menggunakan frasa Wittgenstein) berkorelasi dengan suatu bentuk kehidupan tertentu... demikian juga suatu tradisi religius. Doktrindoktrinnya, kisah-kisah kosmis atau mitos-mitosnya, dan anjuran-anjuran etisnya secara integral terkait dengan sentimen-sentimen pun pengalaman-pengalaman yang dipantiknya, aksi-aksi yang dianjurkannya, serta institusi-institusi yang dikembangkannya (Lindbeck, 1984: 33).

Secara sederhana, kesejajaran antara konseptualisasi agama menurut Lindbeck dan konseptualisasi permainan bahasa menurut Wittgenstein dapat disimak dalam tabel berikut (Hovey, 2002: 139):

\begin{tabular}{|c|c|c|}
\hline & Wittgenstein & Lindbeck \\
\hline Lokus & Bahasa & Agama \\
\hline Aturan-aturan & Gramatika & Doktrin \\
\hline Kondisi atau Konteks & Bentuk-bentuk kehidupan & Praktik-praktik religius \\
\hline
\end{tabular}

Sementara, dalam mengonseptualisasikan agama sebagai fenomena yan menyerupai budaya (culture-like), Lindbeck menimba pengaruh dari, antara lain, Clifford Geertz. Dalam hal 
ini, Geertz mendefinisikan budaya sebagai: “... suatu pola makna-makna yang ditransmisikan secara historis dan mewujud dalam simbol-simbol, suatu sistem konsepsi-konsepsi terwariskan dan diungkapkan dalam bentuk-bentuk simbolis yang dengannya orang-orang mengomunikasikan, melanggengkan, serta mengembangkan pengetahuan mengenai dan sikap terhadap kehidupan" (1973: 89).

Lebih lanjut, Geertz pun menyatakan bahwa agama adalah sebuah sistem kultural, dan menjabarkannya sebagai: "Suatu sistem simbol-simbol yang berfungsi untuk menegakkan suasana hati dan motivasi yang bertahan lama pada orang-orang dengan cara merumuskan konsepsi-konsepsi mengenai tatanan umum kemengadaan dan membalut konsepsi-konsepsi tersebut dengan sebuah aura faktualitas sehingga baik suasana hati maupun motivasi tersebut tampak realistis" (1973: 90).

Pengaruh pemikiran Geertz tersebut begitu teraba ketika Lindbeck menyatakan agama sebagai "skema-skema interpretif, yang biasanya diwujudkan dalam mitos-mitos atau narasinarasi yang... membentuk pengalaman dan pengetahuan manusia akan dirinya-sendiri dan dunia" (1984: 32). Adalah terutama dari Geertz, Lindbeck menyadap inspirasi bahwa agama adalah terutama suatu sistem simbolis yang menghubungkan motivasi dan aksi serta memberikan legitimasi ultim bagi pola-pola pemikiran, perasaan, serta perilaku para pemeluknya (1984: 62).

Dengan mengadopsi teori kultural-linguistik, menurut Lindbeck, seseorang bisa menghindarkan diri dari kecenderungan teori kognitif-proposisional untuk membenturkan klaim kebenaran agama yang satu dengan klaim kebenaran agama lainnya. Dalam teori kulturallinguistik, kebenaran tidaklah bersifat ontologis, seperti dalam teori kognitif-proposisional, melainkan bersifat intrasistematis. Dalam teori kultural-linguistik, suatu klaim kebenaran adalah benar bukan ketika ia secara objektif berkorespondensi dengan realitas, melainkan ketika ia bersifat koheren dengan totalitas konteks yang relevan atau bentuk-bentuk kehidupan yang berkelindan dengannya. Maka dari itu, kebenaran klaim dari agama-agama yang berbeda tidak bisa dinilai berdasarkan suatu tolok ukur yang bersifat objektif dan universal. Kebenaran masing-masing klaim tersebut hanya bisa dinilai dari dan dalam sistem simbolis agamanya masing-masing (1984: 64).

Di sisi lain, bagi Lindbeck, teori kultural-linguistik juga bisa mencegah orang supaya tidak tiba pada kesepakatan atau kesepahaman antaragama yang dangkal—yang, menurutnya, sering terjadi ketika seseorang mengusung teori eksperiensial-ekspresif. Sebagaimana telah dipaparkan di atas, Lindbeck, antara lain, menimba pengaruh dari Geertz. Dalam hal ini, Geertz menekankan sekali pentingnya "deskripsi tebal" (thick description) ketika seseorang hendak 
memahami suatu budaya: "Sebagaimana telah saya katakan, maksud dari suatu pendekatan semiotis kepada budaya adalah untuk membantu kita mendapatkan jalan masuk kepada dunia konseptual yang dimukimi oleh subjek-subjek (yang) kita (teliti), sedemikian rupa sehingga, dalam artian tertentu, kita pun bisa bercakap-cakap dan berubah bersama mereka" (Geertz, 1973: 24).

Dengan demikian, kesepakatan atau kesepahaman antaragama tidak bisa bertolak dari pengandaian bahwa agama-agama yang berbeda sejatinya hanyalah ungkapan-ungkapan yang berbeda dari pengalaman batiniah yang satu dan sama. ${ }^{5}$ Kalaupun kesepakatan atau kesepahaman antaragama itu bisa dicapai, ia hanya bisa dicapai ketika masing-masing pihak telah berupaya dengan serius untuk melibatkan diri dalam bentuk-bentuk kehidupan serta praktik-praktik religius dari agama lain. Dengan kata lain, kesepakatan atau kesepahaman antaragama itu mengandaikan pemahaman akan, meminjam ungkapan Geertz, deskripsi tebal dari masing-masing agama yang berbeda-beda.

\section{MENGAPRESIASI SECARA KRITIS TEORI KULTURAL-LINGUISTIK LINDBECK}

Setelah menelisik teori kultural-linguistik Lindbeck secara saksama, menurut saya, menjadi jelas bahwa teori tersebut tidaklah sama sekali menutup diri pada kemungkinan adanya dialog-dialog antaragama. Teori tersebut tidaklah menghadirkan jalan buntu bagi dialog antaragama seperti yang disangka oleh sebagian pihak.

Pertama-tama, melalui teori kultural-linguistiknya, Lindbeck justru menggugat kecenderungan para proposisionalis untuk membenturkan klaim kebenaran agama yang satu dengan klaim kebenaran agama yang lain. Sebuah kecenderungan yang, tentunya, menjadi batu sandungan serius bagi upaya-upaya dialog antaragama.

Lebih lanjut, sebagaimana telah dipaparkan di atas, menurut saya, teori kultural-linguistik Lindbeck justru menantang dan mencerahkan kita untuk melakukan dialog-dialog antaragama secara lebih mendalam. Untuk bisa melakukan dialog antaragama secara mendalam, seseorang pertama-tama harus memberi diri untuk mempelajari, meminjam ungkapan Wittgenstein, permainan bahasa mitra dialognya. Untuk bisa melakukan dialog antaragama secara autentik, seseorang pun pertama-tama harus berupaya memahami, meminjam ungkapan Geertz, deskripsi tebal agama mitra dialognya, yakni dengan serius melibatkan diri dalam bentuk-bentuk kehidupan serta praktik-praktik religius mitra dialognya. 
Dalam hal ini, menurut saya, kita memang perlu mengapresiasi tilikan-tilikan yang dihadirkan oleh teori kultural-linguistik Lindbeck. Dari perspektif kajian poskolonial, teori kognitif-proposisional memunculkan eksklusivisme agama yang, pada gilirannya, melahirkan imperialisme agama Kristen (Barat), di mana agama-agama lain dipandang sebagai, meminjam ungkapan Karl Barth yang masyhur itu, ketidakberimanan (Religion ist Unglaube). ${ }^{6}$

Sepintas lalu, pluralisme yang disokong oleh teori eksperiensial-ekspresif memang tampak lebih baik, karena tidak lagi mengklaim kekristenan sebagai satu-satunya agama dan iman yang benar. Namun, jika kita cermati, dalam pluralisme tersebut, sejatinya, masih ada juga imperialisme agama Kristen (Barat), ketika pengakuan atas kebenaran dan nilai intrinsik agamaagama lain masih diletakkan dalam kerangka konseptual Kristiani. Hal ini menyata, misalnya, ketika Karl Rahner membuka diri pada kemungkinan bahwa dalam diri umat-umat agama lain seseorang bisa menjumpai “orang-orang Kristen anonim" (anonymous Christian). ${ }^{7}$ Oleh sebab itu, menurut saya, pernyataan Mark Heim tepat:

Dalam suatu cara yang tidak langsung tetapi determinatif, kekristenan masih menjadi normatif, seperti halnya sebuah citra negatif fotografi... isi spesifik di dalam siluet kekristenan boleh jadi dibuang dan digantikan oleh isi dari iman lain mana pun. Namun, batas-batas dari citra Kristen masih tetap dan tidak ada kemungkinan bagi agama-agama lain untuk membawa profil mereka sendiri dan mengubah garis besar (citra Kristen tersebut) (1995: 110).

Edward Said memperingatkan kita untuk menyikapi yang lain secara serius (take the Other seriously) (1989: 223). Mengacu kepada peringatan Said tersebut, di satu sisi, teori kognitif-proposisional memang jelas sama sekali tidak mengindahkan yang lain. Dari titik tilik teori kognitif-proposisional yang lain adalah senantiasa lebih rendah, bahkan salah. Namun, di sisi lain, teori eksperiensial-ekspresif juga tidak cukup serius menyikapi perbedaan dari liyaning-liyan. Teori eksperiensial-ekspresif tidak cukup serius melihat keberlainan dari yang lain tersebut, karena yang lain (the other) senantiasa direpresentasikan dalam kategori-kategori dan kerangka-kerangka konseptual diri-sendiri (self).

Dengan demikian, sekali lagi, baik teori kognitif-proposisional maupun teori eksperiensialekspresif, sama-sama memunculkan pola relasi antaragama yang imperialistis, meski dalam rupa yang berbeda: yang pertama dalam bentuk eksklusivisme yang pongah, sementara yang terakhir dalam bentuk misrepresentasi sic misrekognisi yang dangkal, bahkan menyesatkan.

Kembali mengacu ke pendapat Said di atas, menurut saya, teori kultural-linguistik Lindbeck juga menyediakan titik tolak konseptual yang baik bagi upaya-upaya dialog antaragama yang secara serius dan mendalam menyadari serta menyikapi keberlainan yang lain itu. Namun, pertanyaannya adalah mungkinkah dialog antaragama yang serius dan mendalam semacam itu diwujudnyatakan? 
Dalam hal ini, Lindbeck berpendapat bahwa, meski sangat sulit, dialog antar agama semacam itu bukannya sama sekali tidak mungkin dilakukan. Ia menyatakan: "Ada cara-cara untuk mengatasi hambatan ini, misalnya bilingualisme... tetapi bilingualisme yang sejati (belum lagi penguasaan atas beragam bahasa religius) adalah sangat langka dan sulit sebagaimana halnya mempertahankan, secara mendasar, batasan komunikasi ekstramural yang muncul akibat ketakterjemahan hal-ihwal religius" (1997: 427).

Bagi Lindbeck, untuk bisa melakukan dialog antaragama yang mendalam dan autentik, pertama-tama, masing-masing mitra dialog harus menjadi bilingual, bahkan multilingual: masing-masing mereka harus menguasai permainan bahasa (Wittgenstein) serta deskripsi tebal (Geertz) dari agama-agama mitra dialognya. Sama seperti seseorang bisa belajar menguasai lebih dari satu bahasa dan fasih dalam lebih dari satu budaya, orang pun bisa belajar memahami sistem kultural-linguistik dari agama-agama yang berbeda. Namun, sekali lagi, menurut Lindbeck, hal itu adalah teramat sulit untuk dilakukan.

Dalam hal ini, menurut saya, Lindbeck rupanya masih mengandaikan bahwa monolingualisme bersifat a priori terhadap bilingualisme maupun multilingualisme. Sejalan dengan itu, ia pun agaknya masih mengandaikan bahwa monokulturalitas bersifat a priori terhadap hibridisasi kultural. Dengan kata lain, Lindbeck masih mengandaikan bahwa suatu agama adalah bersifat monolingual dan monokultural. Suatu agama adalah sistem monokultural-linguistik.

Di titik inilah, menurut saya, tilikan-tilikan kajian poskolonial sekaligus juga dapat menghadirkan beberapa kritik yang konstruktif bagi posisi Lindbeck. Konstruktif karena kritikkritik tersebut tidak serta-merta mendiskualifikasi arti penting teori kultural-linguistik yang diajukan Lindbeck, melainkan melengkapi dan memperluasnya.

Dalam hal ini, Homi K. Bhabha, misalnya, yang juga menggunakan pendekatan semiotis kepada budaya, menyatakan:

... ketika kita memahami bahwa semua pernyataan dan sistem kultural dikonstruksikan dalam ruang pelafalan yang kontradiktoris dan ambivalen ini, kita mulai memahami bahwa klaimklaim hierarkis mengenai keaslian atau "kemurnian" inheren dari budaya-budaya tidak lagi bisa dipertahankan, bahkan sebelum kita merujuk kepada contoh-contoh sejarah yang menunjukkan hibriditas (budaya-budaya) tersebut (2007: 54-55).

Menurut Bhabha, budaya, sebagai sebuah sistem simbolis, senantiasa terhibridisasi. Gagasan mengenai budaya yang asli atau "murni", tak lagi bisa dipertahankan karena setiap bentuk budaya sejatinya adalah buah dari proses hibridisasi yang berkelanjutan.

Bagi saya, hal yang sama juga berlaku bagi agama, sebagai sebuah, meminjam ungkapan Geertz (yang kemudian diadopsi oleh Lindbeck), sistem kultural. Menurut saya, sistem kultural- 
linguistik dari setiap agama adalah buah dari proses hibridisasi yang berkelanjutan. Dengan demikian, bukan monolingualisme atau monokulturalitas agama yang menjadi titik tolak dari bilingualisme/multilingualisme serta hibridisasi agama. Sebaliknya, justru bilingualisme/ multilungalisme serta hibridisasi itulah yang mengkonstitusi ajaran-ajaran, bentuk-bentuk kehidupan, serta praktik-praktik religius dari suatu agama tertentu.

Masih terkait dengan hibriditas budaya, pandangan seorang Renato Rosaldo pun menarik untuk dicermati. Senada dengan Bhabha, Rosaldo pun berpendapat bahwa gagasan mengenai budaya yang autentik tidak dapat dipertahankan. Bagi antropolog budaya asal Amerika Serikat tersebut, setiap budaya terbentuk melalui proses pinjam-meminjam lintas batas budaya yang berlubang-lubang.

Dalam dunia poskolonial dewasa ini, gagasan mengenai sebuah budaya yang autentik sebagai suatu semesta yang otonom dan inheren secara internal tidak lagi bisa dipertahankan.... Kesalingbergantungan global yang meningkat dengan pesat telah semakin memperjelas bahwa baik "kita" maupun "mereka" tidaklah homogen dan berbatas tegas seperti yang selama ini disangka-sangka. Setiap kita memukimi sebuah dunia interdependen yang dicirikan oleh proses pinjam-meminjam lintas batas-batas nasional dan budaya (Rosaldo, 1989: 217).

Apa yang dikemukakan Rosaldo tersebut, menurut hemat saya, searah dengan pandangan Kathryn Tanner ihwal identitas Kristen. Dalam karya pentingnya, Theories of Culture: A New Agenda for Theology, Tanner, antara lain, mengkritik teori kultural-linguistik Lindbeck yang masih bertolak dari asumsi-asumsi modernis mengenai budaya yang otonom, koheren, dan berbatas tegas. Menurut Tanner, teori kultural-linguistik Lindbeck masih mengandaikan adanya suatu identitas Kristen yang swabatas (self-contained) dan swamuasal (self-originating). Padahal, sejatinya, bagi Tanner, identitas Kristen senantiasa bersifat relasional; sedari awal dibentuk pelbagai material budaya-budaya yang menyekitarinya. Pelbagai material budaya-budaya yang dipinjam tersebut kemudian "dipelintir dan diubah, digunakan dalam cara-cara berbeda, ketika diletakkan pada suatu konteks Kristen yang baru (Tanner, 1997: 112).

Pada masa formatifnya, misalnya, identitas Kristen telah dibentuk dari pelbagai anasir kultural yang dipinjamnya dari budaya Yahudi maupun budaya Gerika-Romawi. Oleh sebab itulah, Tanner menandaskan bahwa "identitas Kristen pada hakikatnya adalah tidak murni dan bercampur baur, yakni suatu identitas hibrida yang senantiasa berbagi pelbagai bentuk kultural baik dari budaya tuan rumahnya maupun dari agama-agama yang lain" (1997: 114).

Selanjutnya, terkait dengan pernyataan Lindbeck bahwa bilingualisme sangat sulit dilakukan karena adanya ketidaksepadanan (incommensurability) dan ketakterjemahkanan (untranslability) di antara agama yang satu dengan yang lainnya, secara sangat menarik, seorang 
Alasdair Macintyre jutru menandaskan bahwa pernyataan semacam itu hanya mungkin dilakukan oleh seseorang yang, sampai kadar tertentu, bilingual atau multilingual (Cahoone, 2005: 162). Dengan kata lain, ketika ia menyatakan bahwa ada ketidaksepadanan dan ketakterjemahan di antara agama-agama yang berbeda, sejatinya, secara implisit, Lindbeck justru mengakui bahwa dirinya adalah seorang bilingual atau multilingual!

Masih mengenai kesulitan untuk menjadi bilingual/multilingual atau multikultural (being bilingual/multilingual or multicultural), bagi saya, pendapat Chang-Yau Hoon juga layak dicermati. Hoon menyatakan: “... menjadi multikultural—lebih dari sekadar memajang suatu pilihan kelompok-kelompok monokultural—adalah perkara di seputar pengakuan atas keberadaan suatu matriks beragam budaya yang berbeda-beda di dalam diri masing-masing individu" (Hoon, 2012: 16).

Dalam hal ini, menurut saya, ketika mengajukan teori kultural-linguistiknya, Lindbeck memang masih belum membuka diri pada kemungkinan bahwa dalam diri seseorang bisa saja dijumpai matriks jamak agama yang berbeda-beda. Padahal, contoh-contoh konkret dari keberadaan matriks jamak agama yang berbeda-beda dalam diri seseorang tersebut, menurut saya, begitu mencolok.

Sebagai sebuah contoh, pada jemaat-jemaat Kristen Jawa-khususnya, mereka yang berasal dari keluarga Muslim_-kita masih bisa menjumpai kebiasaan untuk memanjatkan doa pribadi di tengah malam buta. Praktik yang, menurut saya, amat dipengaruhi oleh praktik salat Tahajud dalam Islam.

Sebuah contoh lain, masih pada jemaat-jemaat Kristen Jawa, kita pun bisa menjumpai pandangan yang menyerupai teori eksperiensial-ekspresif dalam tipologi Lindbeck, di mana agama dipandang sebagai ungkapan dari pengalaman batiniah atas realitas ultim yang satu dan sama. Pandangan semacam ini menyata, antara lain, ketika kata "agama" dipandang sebagai akronim dari agemaning nyawa 'pakaian yang dikenakan jiwa'. Hal ini terjadi bukan karena jemaat-jemaat tersebut telah akrab dan sepakat dengan tesis-tesis Lonergan yang telah disinggung di atas. Boleh jadi mereka bahkan belum pernah mendengar atau mengetahui siapa itu Lonergan. Hal ini terjadi karena dalam diri jemaat-jemaat tersebut mengada bukan hanya satu, melainkan setidaknya dua matriks religiositas yang berbeda, yakni religiositas Kristen dan religiositas Jawa (Kejawen).

Terkait dengan contoh-contoh di atas, menurut hemat saya, pernyataan Catherine Cornille menjadi sangat penting untuk dicamkan. Dalam pengantar bagi sebuah bunga rampai yang ia sunting, Cornille menyatakan: 
Suatu kesadaran yang terus meningkat dan meluas mengenai pluralisme agama dewasa ini telah membuat seseorang yang religius tidak sekadar harus memilih agama yang mana, melainkan juga berapa banyak agama di mana ia bermukim. Semakin banyak pribadi menyatakan diri mereka adalah sebagian Yahudi dan sebagian Buddhis, atau sebagian Kristen dan sebagian Hindu, atau seluruhnya Kristen sekaligus seluruhnya Buddhis (2010: 1).

Belakangan ini, fenomena yang disinyalir oleh Cornille tersebut kerap dirujuk dengan terma multiple religious belonging. Cornille sendiri menjabarkan multiple religious belonging sebagai "kesadaran atau keyakinan mengenai kebermukiman dalam lebih dari satu tradisi agama" (2010: 1). Sementara, dari titik tilik Kristen, Peter C. Phan menjabarkannya secara lebih elaboratif sebagai:

... fakta bahwa sebagian umat Kristen meyakini bahwa adalah mungkin bahkan penting untuk tidak sekadar menerima secara teoretis pelbagai doktrin atau praktik dari agama-agama lain serta menggabungkannya, mungkin dalam bentuk-bentuk yang telah dimodifikasi, ke dalam kekristenan, tetapi juga untuk mengadopsi serta menghidupi keyakinan-keyakinan, aturan-aturan moral, ritualritual, serta praktik-praktik monastik dari tradisi-tradisi religius selain Kristen, bahkan mungkin juga untuk menjadi bagian dari komunitas penghayat agama-agama lain (2003: 497).

Pertanyaannya, tentu saja, adalah mengapa Lindbeck masih belum membuka diri pada kemungkinan bahwa dalam diri seseorang bisa saja dijumpai matriks jamak agama yang berbedabeda? Mengapa ia seolah abai belaka kepada fakta-fakta yang menunjuk kepada adanya multiple religious belonging seperti yang disinyalir oleh Cornille dan Phan?

Bagi Jeannine H. Fletcher, hal itu terjadi karena Lindbeck tidak pernah menyentuh isu hibriditas individual. Dalam mengajukan teori kultural-linguistiknya, Lindbeck masih terpreokupasi pada identitas komunal yang diskret. Dengan kata lain, menurut Fletcher, penekanan Lindbeck pada identitas kultural-linguistik yang mengkonstitusi suatu komunitas religius membuatnya abai pada fakta hibriditas identitas individual. Sementara, bagi Fletcher, identitas religius seseorang senantiasa bersifat hibrida; dibentuk dalam proses negosiasi berkelanjutan dalam jejaring relasi kultural intrareligius maupun interreligius (Daggers, 2013: 165-167).

Jika sinyalemen Fletcher tepat, maka hal itu patut disayangkan. Menurut hemat saya, sejatinya, penekanan Lindbeck bahwa untuk bisa melakukan dialog antaragama yang mendalam dan autentik, pertama-tama, masing-masing mitra dialog harus menjadi bilingual, bahkan multilingual - masing-masing mereka harus menguasai permainan bahasa serta deskripsi tebal dari agama-agama mitra dialognya - justru menunjuk kepada salah satu dimensi penting dari dinamika multiple religious belonging. 
Dalam hal ini, upaya Phan untuk mengidentifikasi beberapa dimensi dinamika multiple religius belonging penting untuk dicermati. Tanpa bermaksud untuk menjadikannya sebagai suatu kerangka normatif, Phan mengajukan beberapa dimensi dinamika multiple religious yang ia jumpai ketika merefleksikan pengalaman hidup konkret para pionir-seperti Swami Abhishiktananda, Hugo M. Enomiya-Lassakke, Thomas Merton, Bede Griffiths, Raimundo Panikkar, Michael Rodrigo, dan Aloysius Pieris-yang berupaya dengan keras memadukan komitmen mereka pada kekristenan dan pengalaman iman yang lain dalam ziarah hidup mereka. Dan, salah satu dimensi tersebut, menurut Phan adalah:

\footnotetext{
... mengenakan kasut penghayat agama yang lain dan sedapat mungkin mencoba mendapatkan pengalaman religius yang sama dengan penghayat tersebut... Dan, untuk melakukannya, bagaimanapun juga, bimbingan dari seorang guru dari tradisi agama tersebut adalah sebuah keniscayaan. Abhishiktananda memohon bimbingan dari Sri Ramana Maharsni dan Swami Gnanananda. Sementara, Pieris harus bersujud di kaki seorang rahib Buddhis yang terpelajar, memohon supaya dirinya diterima sebagai seorang siswa dan diperkenankan hidup di kompleks biara Buddhis (2003: 511-512).
}

Secara sederhana, menurut saya, apa yang dilakukan oleh Abhishiktananda dan Pieris yang dirujuk oleh Phan tersebut adalah contoh-contoh dari upaya untuk sungguh-sungguh mempelajari dan menguasai baik permainan bahasa maupun deskripsi tebal dari agama-agama mitra dialog mereka. Dengan kata lain, apa yang telah dilakukan oleh pribadi-pribadi eksemplaris seperti Abhishiktananda dan Pieris adalah contoh-contoh perjuangan untuk menjadi, meminjam ungkapan Lindbeck, bilingual atau multilingual.

Lebih lanjut, keberadaan sederet nama yang dinyatakan Phan sebagai pionir tersebut, menurut saya, menunjukkan bahwa, meski sulit, bilingualisme atau multilingualisme yang dimaksud oleh Lindbeck bukanlah sesuatu yang muhal.

Dengan demikian, di satu sisi, konseptualisasi agama sebagai sebuah sistem kulturallinguistik yang diajukan Lindbeck memang perlu diapresiasi. Begitu pula dengan peringatannya bahwa dialog-dialog antaragama yang autentik dan mendalam harus dilakukan secara serius berupaya memahami permainan bahasa serta deskripsi tebal agama yang lain. Namun, di sisi lain, teori kultural-linguistik juga bisa dan perlu diperluas dengan mempertimbangkan juga hibridisasi sistem kultural-linguistik agama serta kemungkinan adanya lebih dari satu matriks sistem kultural-linguistik agama dalam diri seseorang. 


\section{KESIMPULAN: BUKAN JALAN BUNTU, MELAINKAN SETAPAK TERJAL}

Dari diskusi-diskusi di atas, saya tiba pada kesimpulan bahwa teori kultural-linguistik Lindbeck tidaklah menghadirkan jalan buntu bagi dialog antaragama. Sebaliknya, teori tersebut justru memberikan sumbangsih penting bagi upaya-upaya untuk melakukan dialog antaragama.

Teori tersebut menunjukkan dengan sangat baik bahwa setapak dialog antaragama adalah sebuah setapak yang terjal. Setapak itu terjal karena siapa pun yang hendak menitinya, pertamatama, harus bersedia untuk memberi diri belajar, meminjam ungkapan Wittgenstein, permainan bahasa mitra dialognya; berupaya memahami, meminjam ungkapan Geertz, deskripsi tebal agama mitra dialognya, yakni dengan serius melibatkan diri dalam bentuk-bentuk kehidupan serta praktik-praktik religius mitra dialognya.

Namun, di sisi lain, beberapa tilikan kajian poskolonial, menurut saya, menunjukkan bahwa teori kultural-linguistik Lindbeck masih belum mempertimbangkan hibridisasi agama pun kemungkinan adanya jamak matriks keberagamaan dalam diri seseorang. Padahal, jika saja Lindbeck mempertimbangkan kesemuanya itu, boleh jadi ia akan sadar bahwa meski setapak dialog antaragama adalah terjal, tetapi setapak itu tidaklah securam yang ia bayangkan.

Dengan demikian, teori kultural-linguistik Lindbeck, alih-alih mendiskualifikasi, justru bisa meneguhkan dan memperdalam makna sesanti yang dikumandangkan oleh Syafa'atun Almirzanah (2009): to be religious today is to be interreligious. Dengan demikian, harapan Peter C. Phan (2004) mengenai menjadi religius secara interreligius (being religious interreligiously) bukanlah sekadar impian kosong di tengah wacana (teologi) posliberal sekaligus poskolonial ini.

\section{Catatan}

1 Dalam kajian psikologi sosial, antagonisme kelompok (group antagonism) didefinisikan sebagai sikap dan perilaku negatif yang ditunjukkan oleh anggota-anggota suatu kelompok (in-group) kepada anggota-anggota kelompok yang lain (out-group) (Taylor et al., 2006: 170).

2 Namun, bagi Lindbeck, dalam hal ini, Lonergan terutama tengah berbicara sebagai seorang teolog Kristen ketimbang sebagai seorang teoretikus agama. Bahwa Lonergan terutama tengah berbicara sebagai seorang teolog Kristen, menurut Lindbeck, menyata ketika ia menegaskan bahwa, dalam agama-agama biblis, sumber atau norma dari ungkapan-ungkapan pun objektivikasi-objektivikasinya tidak hanya pengalaman inti akan anugerah kasih Allah, tetapi juga kehendak Allah untuk menyatakan diri pada manusia (God's revelatory will). Pernyataan diri Allah itulah yang, menurut Lonergan, menjadi norma bagi kesesuaian dan kememadaian upaya-upaya untuk mengungkapkan atau mengobjektifikasi pengalaman inti akan anugerah kasih Allah. Lonergan tentu memiliki alasan-alasan teologis mendalam yang mendasari pandangan atau teorinya mengenai agama. Namun, menurut Lindbeck, pandangan atau teori tersebut akan menjadi begitu problematis jika ditilik secara non-teologis atau dari titik tilik agama-agama lain. 
Oleh sebab itulah, menurut Lindbeck, teori agama yang diajukan Lonergan bukanlah sebuah teori eksperiensialekspresif dalam arti ketat, melainkan lebih merupakan sebuah teori yang berupaya mensintesiskan pendekatan kognitif-proposisional dan pendekatan eksperiensial-ekspresif mengenai agama.

3 Sejatinya, Lindbeck bukanlah yang kali pertama menyadari bahwa teori kognitif-proposisional dan teori eksperiensial-ekspresif mengenai agama adalah tidak memadai. Di samping itu, telah ada juga upaya-upaya untuk mengajukan teori-teori alternatif. Lindbeck sendiri bukannya abai kepada keberadaan teori-teori tersebut. Hanya saja, menurutnya, teori-teori alternatif tersebut cenderung sekadar berupaya memadukan dimensi kognitifproposisional agama dengan dimensi ekspresi-simbolisnya. Dengan kata lain, teori-teori tersebut, bagi Lindbeck, adalah sekadar upaya untuk mensintesiskan teori kognitif-proposisional dan teori eksperiensial-ekspresif.

Di satu sisi, teori-teori sintetis tersebut memang memberikan gambaran yang lebih lengkap mengenai agama. Namun, di sisi lain, menurut Lindbeck, teori-teori sintetis tersebut cenderung menjadi begitu rumit, sehingga sulit sekali dipahami. "Bahkan dalam bentuk terbaiknya, seperti yang diajukan oleh Rahner dan Lonergan," tegas Lindbeck, "teori-teori tersebut berakhir sebagai akrobat-akrobat intelektual yang rumit... yang terlalu ganjil dan rumit untuk bisa dipahami dengan mudah dan meyakinkan” (1984: 17).

4 Meski, dengan terbuka, Lindbeck juga mengakui bahwa cara-caranya dalam memanfaatkan pengaruh pemikiran Wittgenstein mungkin sekali tidak akan disetujui oleh pihak-pihak yang lebih memahami Wittgenstein ketimbang dirinya.

5 Dalam hal ini, menurut Lindbeck, teori kultural-linguistik yang ia ajukan menolak pengandaian teori eksperiensial-ekspresif bahwa ungkapan-ungkapan eksternal agama adalah turunan dari pengalaman batiniah. Dari titik tilik teori kultural-linguistik, yang terjadi justru sebaliknya: Suatu agama, di atas segalanya, adalah suatu kata eksternal, suatu verbum externum, yang mencetak dan membentuk diri dan dunianya, bukannya sebuah ungkapan atau tematisasi dari suatu diri yang telah berpraeksistensi maupun suatu pengalaman yang bersifat prakonseptual (1984: 34). Bukan pengalaman batiniah yang mendeterminasi ungkapan-ungkapan agama, melainkan sistem simbolis agamalah yang membentuk pengalaman batiniah seseorang.

6 Sejatinya, ketika menyatakan “agama”, Barth sedang terutama merujuk kepada kekristenan. Bagi Barth, keterlibatan dalam agama Kristen, secara paradoksal, justru bisa membuat seseorang menjadi tidak beriman. Dalam hal ini, perlu diingat bahwa konteks pernyataan Barth adalah situasi Jerman di masa rezim Nazi, di mana banyak gereja justru memberikan dukungan kepada totalitarianisme Adolf Hitler (Odagaki, 1997: 124). Namun, sayangnya, kerap kali, pernyataan Barth tersebut kemudian disalahpahami. Kata "agama” kemudian digunakan untuk merujuk kepada agama-agama selain Kristen. Saya meminjam ungkapan Barth tersebut dalam pengertian yang terakhir, yang salah kaprah ini, karena memang kerap kali demikianlah orang memahami ungkapan teolog Protestan yang disebut Paus Pius XII sebagai teolog Kristen terbesar setelah Thomas Aquinas itu.

7 Dalam hal ini, sejatinya maksud Rahner sangat terpuji. Dengan mengajukan neologisme "orang Kristen anonim", Rahner berharap dapat memberikan dorongan bagi orang-orang Kristen untuk berjumpa dengan umat agama-agama lain, karena, dalam perjumpaan tersebut, orang-orang Kristen bisa mengantisipasi kehadiran kebenaran Kristiani, bahkan kehadiran Kristus dalam agama-agama lain (Rahner, 1981: 41).

\section{DAFTAR PUSTAKA}

\section{Almirzanah, Syafa'atun. 2009. When Mystic Masters Meet: Paradigma Baru dalam Relasi Umat} Kristiani-Muslim, Jakarta: Gramedia. 
Bhabha, Homi K. 2007. The Location of Culture, London: Routledge.

Brockman, David R. 2011. No Longer the Same: Religious Others and the Liberation of Christian Theology, New York: Palgrave Macmillan.

Cahoone, Lawrence E. 2005. Cultural Revolutions: Reasons versus Culture in Philosophy, Politics, and Jihad, Pennsylvania: The Pennsylvanisa State Univesity Press.

Cornille, Catherine. 2010. "The Dynamics of Multiple Belonging”. Many Mansions? Multiple Religious Belonging and Christian Identity, Catherine Cornille (ed.), Eugene, Oregon: Wipf and Stock Publishers.

Geertz, Clifford. 1973. The Interpretation of Cultures, New York: Basic Books.

Heim, Mark. 1995. Salvations: Truth and Difference in Religion, Maryknoll, New York: Orbis.

Hoon, Chang-Yau. 2012. Identitas Tionghoa Pasca-Suharto: Budaya, Politik, dan Media, Jakarta: Yayasan Nabil dan LP3ES.

Hovey, Craig. 2002. "Truth in Wittgenstein, Truth in Lindbeck", The Asbury Theological Journal, Vol. 57, No. 1, h. 137-142.

Lindbeck, George A. 1984. The Nature of Doctrine: Religion and Theology in a Postliberal Age, Philadelphia: The Westminster Press.

. 1997. “The Gospel's Uniqueness: Election and Untranslability”, Modern Theology 13, h. $423-450$.

Moyaert, Marriane. 2010. "Absorption or Hospitality: Two Approaches to the Tension between Identity and Alterity", Interreligious Hermeneutics, Catherine Cornille dan Christopher Conway (ed.), Eugene, Oregon: Wipf and Stock Publishers.

Odagaki, Masaya. 1997. “Theology After 1970”, A History of Japanese Theology, Yasuo Furuya (ed.), Grand Rapids, Michigan: William B. Eerdmans Publishing Company.

Phan, Peter C. 2003. "Multiple Religious Belonging: Opportunities and Challenges for Theology and Church", Theological Studies 64, h. 495-519.

. 2004. Being Religious Interreligiously: Asian Perspectives on Interfaith Dialogue, Maryknoll, New York: Orbis.

Rahner, Karl. 1981. “Jesus Christ in Non-Christian Religion”, Theological Investigations, Vol. 17, Terj. Margaret Kohl, London: Darton, Longman, and Todd. 
Rosaldo, Renato. 1989. Culture and Truth: The Remaking of Social Analysis, Boston: Beacon Press.

Said, Edward. 1989. "Representing the Colonized: Anthropology's Interlocutor”, Critical Inquiry 15, h. 205-225.

Tanner, Kathryn. 1997. Theories of Culture: A New Agenda for Theology, Minneapolis: Fortress Press.

Taylor, Shelley E. et al. 2006. Social Psychology (Twelfth Edition), New York: Pearson Prentice Hall. 